\title{
Poesia e violência no berço da linguagem silenciosa: o caso de Chaplin
}

\author{
Ciro Inácio Marcondes \\ Doutor; Universidade Católica de Brasília, Brasília, DF \\ ciroimarcondes@hotmail.com
}

\section{Resumo}

A carreira de Charles Chaplin, especialmente em sua fase na Keystone, tem um fundamento na violência. Ou em duas violências: a primeira, a violência física das trombadas e pontapés que seu personagem Carlitos desfere em seus antagonistas; e a segunda, a violência motora, do movimento incessante pelo campo cinematográfico e através dos planos. Propomos uma análise desta dupla valência da violência em Chaplin como princípio fundador da poesia cinematográfica silenciosa: como esta violência motora e física se transforma em balé? Será analisada a trajetória de Chaplin em seus primeiros curtas por meio de uma reconstrução narrativa e histórica do cinema, em busca do nascimento da poesia fílmica.

\section{Palavras-chave}

Charles Chaplin. Poesia cinematográfica. Cinema silencioso. Violência. Teoria do cinema.

\begin{abstract}
"Surpreendeu-me que eu estava testemunhando uma arte morta, um gênero totalmente defunto que jamais seria praticado novamente. E mesmo assim, com todas as mudanças que ocorreram desde então, o trabalho deles estava tão vivo e revigorante quanto na época em que fora mostrado pela primeira vez. Isso ocorreu porque eles tinham entendido a língua que estavam falando. Eles tinham inventado uma sintaxe para o olho, uma gramática de pura cinética e, exceto pelas fantasias, pelos carros e pelo mobiliário singular nos cenários, nada daquilo poderia envelhecer. Era o pensamento traduzido em ação, a vontade humana expressando-se através do corpo humano, e portanto isso era para sempre. A maioria das comédias silenciosas pouco se importavam em contar histórias. Elas eram como poemas, como a representação de sonhos, como alguma intrincada
\end{abstract}


coreografia do espírito". (AUSTER, 2002¹ apud KOBEL, 2008, p. 55, tradução nossa).

Por que abordar Charles Chaplin? Esta epígrafe retirada de um romance do escritor americano Paul Auster a respeito de um personagem que pesquisa a vida de um comediante de cinema silencioso (ao estilo de Chaplin) pode ser um bom gatilho para explicar esta opção. Quer estivesse falando de Chaplin, ou Buster Keaton, ou Harold Lloyd, ou Mack Sennet, ou Stan Laurel, ou Oliver Hardy, ou Roscoe Arbuckle, ou Mabel Normand, ou Harry Langdon ou qualquer das muitas dezenas de atores e atrizes que personificaram a comédia norte-americana durante o período silencioso do cinema (especialmente entre as décadas de 1910 e 1920) -, quer estivesse falando de espécie de síntese do universo destes artistas todos, Auster (2002 apud KOBEL, 2008, p. 55, tradução nossa) guardou em seu texto uma importante preocupação: a de procurar definir a comédia silenciosa (e, por extensão, talvez todo o cinema silencioso) como um meio específico de produção de conhecimento. 0 esforço do escritor, por meio do narrador-personagem, em explicar este tipo de cinema como linguagem, como algo cuja estrutura não se perde com a passagem do tempo, como um sistema autônomo de funcionamento, tudo isso contribui para pensarmos Chaplin como uma posição estratégica, no âmbito da indústria, da economia e da estética, para o pensamento sobre o cinema silencioso.

Por que isso? Vejamos certas passagens cruciais do texto de Auster (2002 apud KOBEL, 2008, p. 55, tradução nossa), colocadas em ordem estratégica: "[...] o trabalho deles estava tão vivo e revigorante quanto na época em que fora mostrado pela primeira vez.". Esta é uma primeira e importante premissa: o cinema silencioso não é uma forma de arte e comunicação do passado, obsoleta ou irrecuperável. Em um período de transformações hipervelozes como o século XX, o ciclo de nascimento, estabelecimento, consolidação e decaimento do cinema silencioso como forma cultural de expressão se fechou em poucas décadas, algo que formas de arte antigas levaram séculos para atingir. Porém, como ressalta o personagem de Auster (2002 apud KOBEL, 2008, p. 55, tradução nossa), seu mecanismo de expressão pertence à realidade, à sensibilidade, à cognição. É um tipo de autopoiese. É

\footnotetext{
${ }^{1}$ AUSTER, Paul. The book of illusions. London: Faber\&Faber, 2002. P. 44-45. . No original: It struck me that I was witnessing a dead art, a wholly defunct genre that would never be practiced again. And yet, for all the changes that had occurred since then, their work was as fresh and invigorating as it has been when it was first shown. That was because they had understood the language they were speaking. They had invented a syntax of the eye, a grammar of pure kinesis, and except for the costumes and the cars and the quaint furniture in the background, none of it could possibly grow old. It was thought translated into action, human will expressing intself through the human body, and therefore it was for all time. Most silent comedies hardly even bothered to tell stories. They were like poems, like the rendering of dreams, like some intricate choreography of the spirit.
} 
neste sentido que o autor nos informa que aquele tipo de expressão jamais poderia envelhecer.

Seguindo por este caminho, Auster (2002 apud KOBEL, 2008, p. 55, tradução nossa) menciona: "Isso ocorreu porque eles tinham entendido a língua que estavam falando. Eles tinham inventado uma sintaxe para o olho, uma gramática de pura cinética [...]". Auster (2002 apud KOBEL, 2008, p. 55, tradução nossa), de maneira literária e intuitiva, prevê uma gramática para este cinema, uma sintaxe do olho. Logicamente, ele não foi o primeiro a preconizar o cinema como língua ou linguagem. Vselovod Pudovkin (2003) e Sergei Eisenstein (2002) se debruçaram longamente sobre o assunto. Buscavam uma unidade mínima de significação que correspondesse ao fonema, à sílaba, algo que pudesse ser decomposto, estruturado, rearranjado, no sentido de multiplicar a semântica. Eram formalistas. Já o teórico Christian Metz (2004) considerava que o cinema era um ótimo emulador de linguagem, um tipo de mecanismo amorfo e imitador que se apropriava das maneiras de funcionar de uma linguagem para produzir também significação. Desta forma, o cinema seria uma espécie de linguagem que poderia transformar suas regras de funcionamento a cada novo filme. Um tipo extraordinário de fenômeno comunicacional que se reinventa, enquanto língua, a cada vez que é acionado novamente. Além de Metz (2004), também o cineasta (e teórico do cinema) Pier Paolo Pasolini (1982) considerava que o cinema era não apenas uma linguagem específica, mas a língua da própria realidade em si. Baseado em uma semiótica livre e atrevida, Pasolini (1982) considera que o cinema captura signos que estão já presentes em uma espécie de língua "natural" da própria realidade, como se a imagem dos filmes fosse inscrição das imagens reais, que, por sua vez, já eram inscrição de algum código presente na fundação da natureza.

A formulação de Auster (2002 apud KOBEL, 2008, p. 55, tradução nossa) pode não ter tão bem definida base semiótica, mas captura a essência do que efetivamente estas imagens reverberam: é pelo olho (imagem, espaço) que se constitui a apreensão do cinema. E é pela cinética (movimento) que a imagem exerce sua replicação do tempo (DELEUZE, 1983). Assim, talvez Auster (2002 apud KOBEL, 2008, p. 55, tradução nossa) queira exprimir literariamente a gramática de uma totalidade espaço-temporal. A maneira como estas coordenadas se tornam língua. Afinal, "Era o pensamento traduzido em ação, a vontade humana expressando-se através do corpo humano [...]" (2002 apud KOBEL, 2008, p. 55, tradução nossa). Aqui, duas coisas: a possibilidade de que as estruturas do pensar possam ser traduzidas em movimento na tela do filme (sendo, portanto, medium); e que a 
vontade humana (ou seja, seu nietzschiano ímpeto vital) possa ser traduzida no gesto humano. São relações cruciais para o entendimento da experiência de se assistir a um filme silencioso. Cinema e linguagem. Imagem, tempo e movimento. Espectatorialidade e cognição. Medium, gesto e vida.

Este excerto possui ainda uma conclusão, corolário de todas as outras proposições, algo que encerra nosso pequeno círculo hermenêutico e nos traz de volta a Charles Chaplin: "A maioria das comédias silenciosas pouco se importavam em contar histórias. Elas eram como poemas, como a representação de sonhos, como alguma intrincada coreografia do espírito [...]" (AUSTER, ANO, p., tradução nossa). Neste momento, Auster (2002 apud KOBEL, 2008, p. 55, tradução nossa) se dá conta de que talvez a investigação a respeito destes filmes pelo viés da linguística e da semiótica simplesmente não contemplasse aquilo que eles naturalmente transmitem, comunicam e inspiram no espectador. A comédia silenciosa não residia necessariamente em uma emulação da língua, ou sequer nas operações da ficcionalidade, e tampouco no registro documental. Ela reside, enfim, oposta à ficção e ao documentário, em um terceiro vértice: a poesia cinematográfica.

Portanto, Chaplin. À parte o status de mito do século XX que o ator e diretor adquiriu ao longo dos anos (que dispensa comentários), chama a atenção o quão precoce foi o fanatismo em torno dele. Chaplin chegou à Keystone, companhia de Mack Sennet, famosa por seus filmes seriados ${ }^{2}$ e amalucados, cheios de perseguições frenéticas e non-sense, em janeiro de 1914. Era sua primeira vez no cinema. Vindo de Londres e pertencendo à companhia de teatro de vaudeville britânica (music hall) de Fred Karno, Chaplin foi visto, praticamente ao acaso, por Sennet, apresentando um espetáculo chamado Uma noite num music hall inglês em um teatro em Nova York (CHAPLIN, 1989). Isso foi durante uma das turnês norte-americanas da trupe de Karno. No início de 1914, chamado para ganhar 125 dólares por semana, Chaplin largou tudo e foi até um subúrbio de Los Angeles para trabalhar na Keystone. Pouco mais de um ano depois, figurava entre os maiores astros do cinema de Hollywood.

A ascensão de Chaplin foi, sem exageros, implacável. Ainda em um período em que o cinema narrativo começava a ganhar solidez (tendo se desenvolvido e se transformado completamente a partir do cinema de atrações, entre 1907 e 1915. Cf. BOWSER, 1990, p. 255-272) e em que o star system hollywoodiano engatinhava e procurava estabelecer suas

\footnotetext{
2 Os serials (filmes seriados) eram muito comuns no cinema dos anos 1910. Tinham produção irregular e continuidade inconstante. Louis Feuillade foi quem teve maior êxito com este formato na França. Nos Estados Unidos, o formato consagrou atores e atrizes como William S. Hart, Pearl White e Mack Sennet.
} 
bases e regras, Chaplin e seu personagem, Carlitos (Charlie), chegaram para dar um rosto a uma forma de cinema que via acontecer uma transformação definitiva tanto em sua maneira de representar (em mudanças drásticas no apelo da linguagem) quanto em sua forma de se vender: o cinema narrativo, os planos próximos, o investimento em personagens fixos nos filmes seriados e na repetição dos atores. Tudo isso contribuiu para a formação de um sistema que colocava o ator no centro não apenas da arte cinematográfica, mas também de sua economia.

Chaplin emerge dentro do processo que, na trajetória do cinema silencioso americano, ficou conhecido como "virada narrativa", que a historiadora Eileen Bowser (1990) situa também como "era dos Nickeodeons", ou seja, o momento em que o cinema perde seu caráter de atração para sofisticar-se por meio do ato de contar histórias por meio de uma série de elementos narrativos e de linguagem sistematizados em procedimentos a princípio disjuntos e concorrentes, e que, depois, vão convergindo em códigos que vão modelar os diferentes tipos de narrativa clássica. David Wark Griffith, especialmente entre 1908 e 1914, quando estava a serviço da companhia Biograph, foi um dos vetores desta transformação. Mesmo assim, o tipo de narrativa desenvolvida por ele durante este período vai perdurar apenas alguns anos (a saber, de meados dos anos 1910 até meados dos anos 1920) até que seja substituído por uma narrativa transparente (Cf. XAVIER, 2005, p. 17-26), em que a estrutura narrativa (ou o narrador propriamente dito) se torne discreta diante da representação contida na história do filme, preocupada em mimetizar a vida em si.

Bowser (1990), ao contrário do que pensa o senso comum da história do cinema ("Griffith inventou a narrativa clássica"), aproxima-o da montagem soviética, cuja estética ele notoriamente influenciou (EISENSTEIN, 2007), chegando a chamar o estilo de montagem griffthiano de "montagem ideológica" (BOWSER, 1990), graças à forte orientação moral de seus curtas-metragens, o que determinou certo padrão temático nos melodramas da época, ao mesmo tempo em que ajudou a linearizar as narrativas cinematográficas. Moralizar o cinema a partir das demandas da audiência, com a sua crescente popularização nesta época, se tornou papel dos produtores, que queriam sua plateia plenamente satisfeita. Esta é uma das razões que Bowser (1990) cita como causa da virada narrativa: os filmes tinham que funcionar como uma parábola moral, e linearizar uma história era uma maneira fácil de fazer isso. Griffith foi importante neste processo.

É dentro deste contexto, em 1914, que Chaplin vai fazer filmes na Keystone. Seu timing é ideal, pois a "virada narrativa" é um dos momentos-chave na história do cinema, 
algo que transformou completamente tanto a maneira com que os filmes são representados e percebidos, quanto a maneira com que são vendidos. Não à toa, Chaplin fundaria, em 1919, juntamente com Griffith (além dos astros Mary Pickford e Douglas Fairbanks), o estúdio United Artists, cuja principal diretriz era voltar a dar autoridade cinematográfica ao diretor. Porém, entre os dois (Griffith e Chaplin) havia diferenças evidentes. Em primeiro lugar, estilísticas: enquanto Griffith era virtuoso e cinético, abusando de movimentos de câmera e procedimentos arrojados de montagem, Chaplin optava por um cinema simples - ainda que a condução geral das histórias ocorresse no modelo griffthiano -, de câmera parada e pouca variação de angulação, privilegiando a mise-en-scène e a performance corporal dos atores. Em segundo lugar, o gênero: Griffith era um mestre nos melodramas, gênero que ele ajudou consolidar no cinema, e Chaplin, como se sabe, sobressaiu-se na comédia (ainda que, em sua carreira nos anos 1920, misturasse com frequência os dois gêneros, tornando-se uma marca registrada do Chaplin maduro). Por fim, e o que mais nos interessa aqui, é uma diferença ideológica entre os dois: Griffith, um homem conservador ${ }^{3}$, era filho de um coronel do exército confederado durante a Guerra Civil Americana, e fazia filmes que sustentavam uma moral cristã e tradicional, bem ao gosto das demandas do público da época. Já Chaplin, pelo contrário, tendo crescido nos subúrbios de uma Londres vitoriana violenta, encarnou em seu personagem (Carlitos ou "o Vagabundo") um sujeito contraditório, afeito a mesquinharias como roubar ou agredir, ao mesmo tempo em que poderia ser amável, gentil e completamente desapegado.

Chaplin passou por quatro estúdios (Keystone, Essaney, Mutual e First National) e participou de mais de 60 curtas-metragens até que realizasse seu primeiro longa-metragem, O garoto (1921). Muito antes de grandes sucessos pelos quais é conhecido até hoje, Chaplin já era uma celebridade que atraía milhões aos cinemas. Talvez tenha sido a primeira de proporções colossais. Ainda em 1915, quando estava na Keystone (portanto, seu primeiro ano no cinema), Chaplin já aparecia em histórias em quadrinhos, cartoons em revistas, e brindes com a cara dele eram oferecidos nos jornais (MALAND, 2004). 0 crítico Charles J. McGuirk, da Motion Picture Magazine, foi o primeiro a chamá-lo de gênio, ainda em 1915. "Uma vez em cada século [...] um homem nasce com a capacidade de colorir e influenciar seu

\footnotetext{
3 É notório o racismo com que Griffith abordou os negros em seu clássico sobre a Guerra Civil Americana $O$ nascimento de uma nação (The birth of a nation, 1914). Everson (1998, p. 84, tradução nossa) explica suas influências: "Se o filme parece ser anti-negro às vezes, isso pode ser entendido, pois os soldados e oficiais confederados que aconselharam Griffith tinham opiniões fortes e óbvias sobre a guerra e sobre os negros também."
} 
mundo. [...] Charles Chaplin está fazendo isso com pantomima e personalidade." (MCGUIRK, $1915^{4}$ apud MALAND, 2004, p. 203, tradução nossa).

Chaplin angariou enorme popularidade com um ano de carreira. Os muitos anos vindouros seriam ainda melhores, elevando-o, enquanto presença midiática, a patamares poucas vezes pareados na história. Foi, efetivamente, o primeiro grande nome da reprodutibilidade técnica, e seu rosto e o de seu personagem suplantaram a sua individualidade. Sua imagem e a de seu personagem tornaram-se estilemas para qualquer assunto relacionado ao cinema, em especial ao cinema silencioso.

Mas o que fez de Chaplin, com sua linguagem simples, uma personificação do que pode representar o cinema silencioso? 0 que o difere de Griffith, que, a despeito de sua gigante popularidade na era muda e importância na trajetória formal do cinema, é praticamente desconhecido do público em geral, sendo seus filmes muito menos exibidos do que os de Chaplin? A resposta pode estar também em três vértices: a violência, o gesto e o movimento. Para pensarmos o primeiro item, é necessário voltarmos a seus curtas e pensarmos a trajetória de Chaplin ao mesmo tempo como um desenvolvimento programático (tendo seu estilo e personagem se transformado por questões mercadológicas e também artísticas através do tempo) e como um resíduo (ou reminiscência) que sempre esteve lá. E, de certa forma, a estética de Chaplin, se o levou a um equilíbrio delicado de afecções melodramáticas e humanísticas (como em Luzes da cidade (1931) ou O grande ditador (1940)), com um tipo de humor refinado e elaborado com a colaboração de um contato cada vez mais íntimo com os procedimentos do cinema (O circo (1928), Em busca do ouro (1925)), ela preservou também aquilo que originou todo este sólido equilíbrio na cabeça do cineasta, aquilo que primeira e ultimamente encantou as plateias do cinema silencioso: a violência de Carlitos.

O Carlitos dos curtas-metragens é conhecido por originar pequenas metonímias de suas grandes obras dos anos 1920. Seria o embrião do grande Chaplin. Isso, no entanto, não ocorreu exatamente assim. Se uma parte de Chaplin foi meticulosamente construída e planejada pela sua personalidade ambiciosa, a outra veio de condições não só do cinema que primeiro o acolheu (o slapstick americano de Mack Sennett), como de sua experiência pregressa, tanto em sua história pessoal quanto sua formação no music-hall inglês, com seu humor de certa forma degenerado, escatológico, violento. Chaplin encontrou nas corridas e

\footnotetext{
${ }^{4}$ MCGUIRK, Charles J. “Chaplinitis”, Motion Picture Magazine 9: 6-7 (Julho e Agosto de 1915). Part 1, p. 87. No original: “Once in every century [...] a man is born who is able to color and influence his world. [...] Charles Chaplin is doing it with pantomime and personality."
} 
perseguições amalucadas de Sennett uma maneira de fazer certa sinergia entre as comédias inglesa e americana da época. Cabe aqui a precisa descrição que o clássico historiador Georges Sadoul (1963) reservou a Sennett em sua História do cinema mundial:

O estilo de Mack Sennett é fluido, preciso, ágil, ele soube dosar a progressão e utilizar a montagem com uma exatidão que aprendeu com Griffith. A loucura e a liberdade são os distintivos de uma obra na qual as trucagens tornavam possíveis as mais inverossímeis façanhas: motociclistas usavam os fios do telégrafo como pista, os automóveis saltavam por cima dos bondes, tipos atléticos brandiam os vencidos como se estes fossem fundas. Pular um muro de pés juntos era brincadeira, como também cair de um sexto andar. Esse gosto pelo inverossímil desapareceu hoje da comédia, mas subsiste nos desenhos animados. (SADOUL, 1963, p. 108-109).

Sennett havia sido figurante em filmes de Griffith, e seu estilo, de perseguição amalucada, seguia não apenas os princípios que o diretor de Intolerância (1916) vinha desenvolvendo em centenas de curtas-metragens desde 1908, como também a tradição da chamada "escola de Brighton" (Cf. SADOUL, 1963, p. 39-44), grupo de cineastas britânicos que, durante a primeira década do novo século, desenvolveram alguns fundamentos do que se tornaria a linguagem do cinema, como a continuidade em contiguidade, os cortes analíticos, o close-up, etc. Esta motricidade, característica deste tipo de filme, foi fundamental para instaurar no espectador um sentido de continuidade primeva, eletrizar o cinema com verdadeira cinética e impulsionar o olhar para fora do campo, buscando sempre a continuação da ação pregressa. No início, a simples perseguição em si bastava. E a violência era a combustão para que a correria e a algazarra irrompessem nestes filmes. Quase todos os filmes dos Keystone Kops eram baseados neste princípio. Chaplin, no início, adaptava-se a esta fórmula. Como a Keystone, mesmo sendo um jovem estúdio, já tinha seu time de "estrelas" nesta época, Chaplin teve de filmar várias vezes no modelo "dupla" antes que pudesse protagonizar e dirigir seus próprios filmes. Uma das duplas que realizou foi com Roscoe "Fatty" Arbuckle (conhecido no Brasil como Chico Boia), um ator cômico que mais tarde faria par também com Buster Keaton (Cf. A garagem, 1920). A dupla com Chaplin teria inspirado Laurel e Hardy a seguirem a fórmula para criar 0 gordo e o magro, já nos anos 1920. Em Na farra (The rounders, 1914), presenciamos uma pantomima crua em cinco cenários e duas locações simples em que, basicamente, dois bêbados (Chaplin e Arbuckle) tentam fugir de suas respectivas esposas para continuarem bebendo. A instauração do 
movimento (quando os personagens são jogados de um cenário a outro - um truque comum dos estúdios da época presente também em outros filmes de Chaplin como Casa de penhores (1916) e o ritmo frenético com que a trapalhadas ocorrem são gerados por elementos de violência: as mulheres batem nos homens, que fogem. 0 princípio é o mesmo em Carlitos $e$ Mabel se casam (1914), também da Keystone, quando Chaplin contracena com Mabel Normand, uma atriz cômica de sucesso que estava no estúdio antes dele. Normand, então com cerca de 20 anos, foi uma das primeiras mulheres a ter sucesso na direção em Hollywood. Ao contrário de Edna Purviance, com quem Chaplin contracenou em inúmeros filmes (e com que sem envolveu romanticamente), que fazia basicamente papéis dramáticos, Normand não apenas protagonizava os filmes que dirigia (como Carlitos e as salsichas [1914]), como também se especializou no humor. Em Carlitos e Mabel se casam (1914, Figura 1), dois casais (incluindo um com Normand e Chaplin) flertam um com os cônjuges do outro de maneira deslavada e (para os padrões da época) quase "imoral". Quadros "confusos" (sem decupagem - em que vários atores contracenam na mesma tomada, Figura 1) se misturam à mesma pantomima violenta de Na farra (1914). A gag básica é: Carlitos bate em um boneco de treinamento de boxe, o boneco cai, retorna e atinge Normand.

Figura 1- Cônjuges flertam e se desentendem

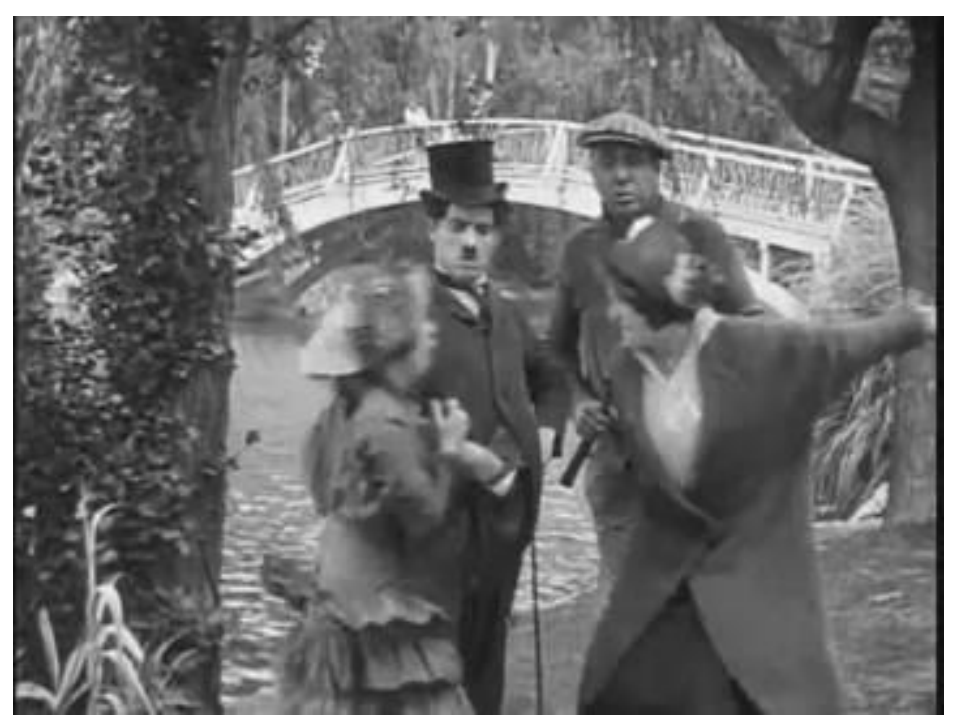

Fonte: Carlitos e Mabel se casam (1914).

A violência destes filmes, logicamente de natureza bufa e diferente da violência exploitation dos filmes contemporâneos, funcionava em princípio como alívio cômico (tornando os filmes muito politicamente incorretos para os padrões de hoje, característica 
do primeiro cinema. Daí a necessidade de uma moralização, conforme vimos em Bowser (1990)) e, em segunda instância, como fator que desencadeia a perseguição. Em Dois heróis (1914), por exemplo, Arbuckle, após perceber que havia perdido uma luta de boxe, saca duas pistolas e começa a atirar, enlouquecido, tentando atingir a plateia (Figura 2). É o momento em que os Keystone Kops saem à sua caça e uma longa sequência de perseguição se inicia nos telhados dos subúrbios de Los Angeles. Quase todos os filmes da Keystone terminavam em brigas, às vezes envolvendo um número grande de personagens. Em Carlitos e as salsichas (1914), Chaplin já se apresenta ao espectador agredindo gratuitamente e assediando mulheres. Quando Normand, a vendedora de salsichas, se vê vítima de valentões, Carlitos aparece para salvá-la, apenas para roubá-la em seguida. Este filme, assim como Dois heróis (1914), termina com uma grotesca briga entre dezenas de personagens, com salsichas voando para toda parte. Como afirma o historiador Charles J. Maland, "A persona de Carlitos que emergiu dos filmes da Keystone era quase sempre malvada, crua e bruta." (MALAND, 2004, p. 199).

Figura 2 - Violência estilizada nos filmes do Roscoe Arbuckle

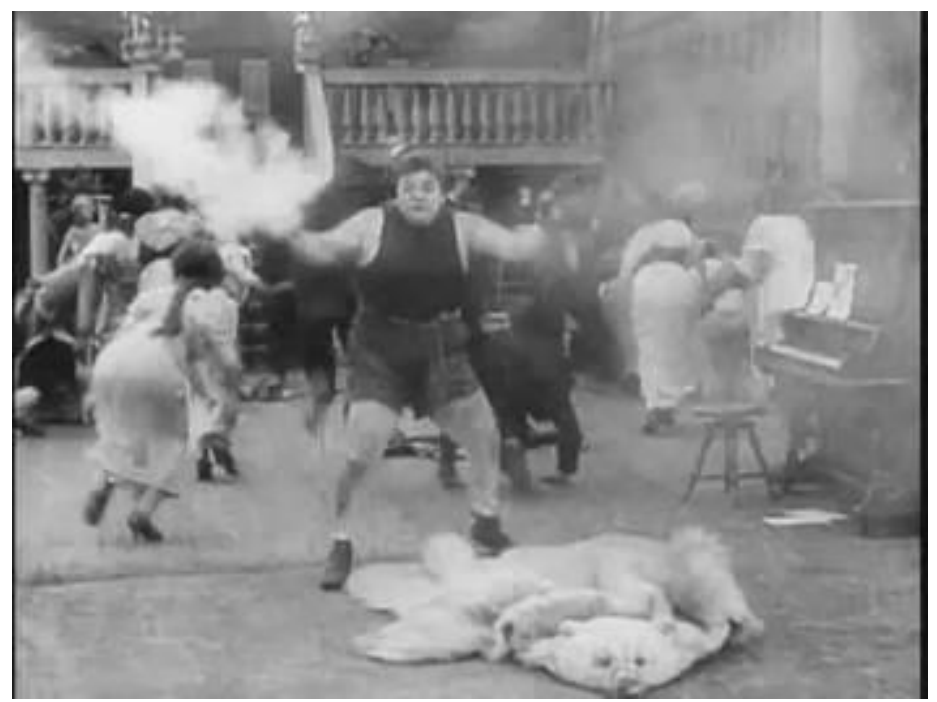

Fonte: Dois heróis (1914).

Mesmo fora da Keystone, como, por exemplo, nos mais vibrantes e "maduros" filmes da Mutual, a violência prevalece nos filmes de Chaplin. Em Rua da paz (1917), Carlitos se alista na polícia e deve controlar uma vizinhança completamente consumida por escroques, bandidos e vigaristas. Um bully gigantesco interpretado por Eric Campbell (ator amigo de Chaplin que reprisou este tipo de personagem - grande, violento e ameaçador - em diversos 
outros filmes, Figura 3) torna-se o centro das atenções, desencadeando violência descontrolada até que, por obra do acaso, Carlitos consegue prendê-lo. Em outro momento, a seringa cheia de drogas de um junkie é acidentalmente injetada em Chaplin que, atordoado, passa a ganhar espécie de superforça capaz de derrotar algozes muito mais fortes do que ele. Esse filme, considerado uma das obras-primas da fase Mutual, parece encadear uma mecânica constante que inclui um jogo de forças de incitação à violência, pacificação e reposição da violência, fatalmente aparecendo como algo maquínico (a produção técnica da violência) conforme Chaplin instauraria, de maneira muito mais consciente, anos depois em Tempos modernos (1936).

\section{Figura 3 - Chaplin e Eric Campbell}

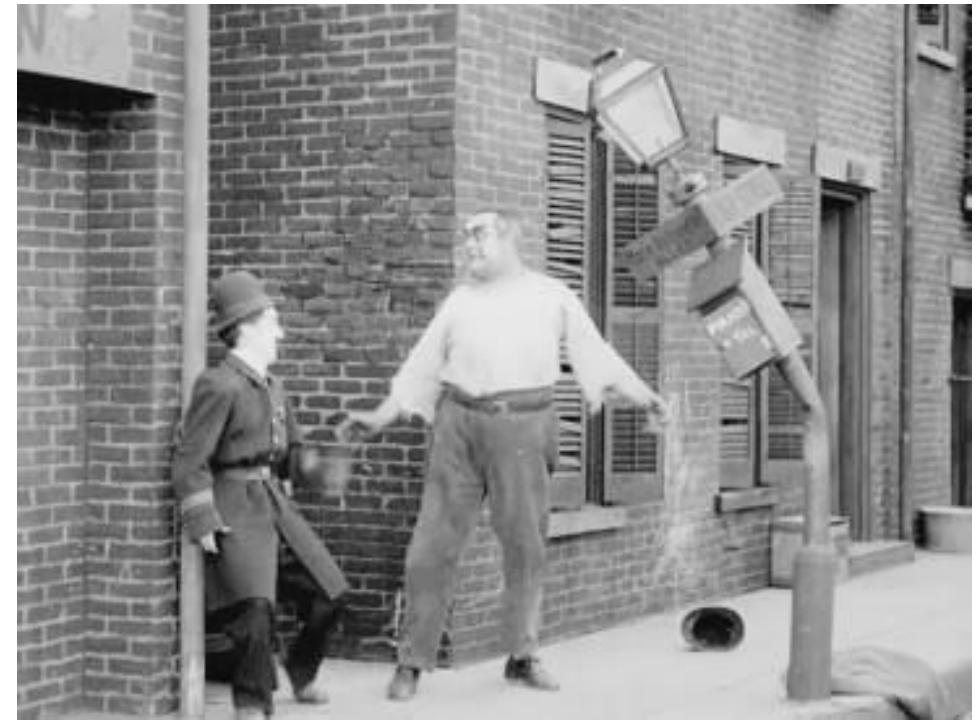

Fonte: Rua da paz (1917).

Esta questão da violência claramente trata de um nascimento. Carlitos nasce em meio à violência, e isso é privilegiado pela linguagem bufa, herdeira da commedia dell'arte, da pantomima elaborada no slapstick. Logicamente, estamos falando de linguagens mudas, e o gesto deste tipo de humor degenerado vai se tornar algo como um clichê, ou ao menos um estereótipo, de como o movimento no cinema silencioso seria visto como ridículo ou anacrônico para as plateias atuais. A questão é que, em primeiro lugar, a motricidade gerada pela necessidade de violência destes filmes vai gerar o fluxo autônomo das imagens do cinema silencioso. Muito em breve, a cinética destes filmes vai falar por si própria, e imagens-movimento se tornarão, conforme descreve Gilles Deleuze (1983), imagens-tempo. Esta passagem não ocorre naturalmente ou ao acaso. 0 nascimento destes dois elementos, 
neste contexto - a saber, a violência e a poesia - é simultâneo e simbiótico. Chaplin, conforme veremos, vai superar este nascimento violento e instituir graça e leveza aos seus filmes, mas, de certa forma, a indistinguibilidade de origem será marca indelével não apenas nele, mas em todo o cinema silencioso. Vários tipos de dicotomia reproduzem este decalque original: som e silêncio; fala e escrita; silêncio e fala; leveza e violência. A filósofa espanhola María Zambrano (1996) subsumiu estes decalques e dicotomias em uma aporia fundacional: a oposição entre filosofia e poesia.

Para Zambrano (1996), tanto a filosofia quanto a poesia nascem de um pasmar-se original diante da matéria da vida. A diferença é que, fundada na violência do conhecimento, a filosofia vai centrar-se em um "buscar" incessante, enquanto a poesia, que não "busca", mas "tem", nasce como uma epistemologia diferente, e proporá um tipo de fusão em tudo oposta a esta "matéria" que a realidade nos oferece em primeira instância.

E desde então o mundo se dividira, sulcado por dois caminhos. 0 caminho da filosofia, em que o filósofo, impulsionado pelo violento amor que buscava, abandonou a superfície do mundo, a generosa imediatez da vida, baseando sua ulterior possessão total em uma primeira renúncia. 0 ascetismo havia sido descoberto como instrumento deste gênero ambicioso de saber. A vida, as coisas, seriam exprimidas de uma maneira implacável, quase cruel. 0 pasmar primeiro será convertido em persistente interrogação; a inquisição do intelecto começou seu próprio martírio e também o da vida. (ZAMBRANO, 1996, p. 16-17, tradução nossa).

Esta violência original encontrada no nascimento da filosofia (a interrogação como violência que, tal qual um bandeirante, precisa desbastar florestas na base do facão para enfim encontrar sentido para o êxtase original diante da matéria da vida) - se considerarmos a filosofia secular como tributária de um logos racionalista - foi também pensada por Jacques Derrida em sua crítica desconstrutiva a Lévi-Strauss quando este coloca a relação entre oralidade (palavra falada) e escrita como submissão violenta (a segunda) e idílio original "extasiado" (a primeira). Derrida, conforme apontado por Johnson (2001), enfoca o desejo de Lévi-Strauss de que esta escala (primeiro a oralidade, depois a escritura - enquanto violência) fosse verdadeira, como se uma ordem autoritária existisse entre oralidade e escritura: 
Em primeiro lugar, embora Derrida exponha convincentemente as inconsistências lógicas e as limitações conceituais do argumento de LéviStrauss, ele está sobretudo interessado no desejo de que uma distinção binária, entre preto e branco, deva existir entre fala e escritura, a primeira como meio de comunicação autêntica e próxima, e a segunda como alienação não natural e autêntica da voz. (JOHNSON, 2001, p. 23).

Ainda que não estejamos falando de fala e escritura, mas sim de filosofia e poesia, podemos concluir que o método de pensar de Lévi-Strauss neste caso, hierárquico e estrutural, se opõe a Zambrano (1996) no sentido de que não considera os dois elementos analisados como gêmeos em princípio indistinguíveis que depois irão ser formulados como métodos distintos de se provar a experiência do mundo (conforme Derrida irá argumentar a respeito da muito maior ambiguidade existente entre fala e escritura). Neste caso, é importante frisar que existem, simultaneamente, a filosofia e a poesia, e que, se ambas podem ser lidas como epistemologias distintas, que seguem caminhos diferentes, elas também podem ser pensadas como pertencendo a um mesmo fenômeno ambíguo. 0 fato de serem geradas a partir do mesmo estupor diante do mundo marca, nestas experiências epistemológicas, uma inseparabilidade do material residual de uma na outra, mesmo quando trilham trajetórias separadas.

Este é, ao que parece, o primeiro frente-a-frente do pensamento e da poesia em seu encontro originário, quando a Filosofia, soberba, se liberta do que foi sua qualidade matriz; quando a Filosofia resolver ser a razão que capta o ser, que, expresso em logos, nos mostra a verdade. A verdade... Como, tendo ela, a filosofia acabou não sendo o único caminho do homem na Terra, até este céu alto e imutável de onde resplandecem as ideias? 0 caminho sim se fez, mas há algo no homem que não é razão, nem ser, nem unidade, nem verdade - esta razão, este ser, esta unidade, esta verdade. Mas isso não era fácil demonstrar, e nem se o queria, porque a poesia não nasceu na polêmica, e sua presença generosa jamais se afirmou polemicamente. Não surgiu contra nada. (ZAMBRANO, 1996, p. 25, tradução nossa).

Há uma bifurcação, portanto, nesta querela entre o pensamento e a poesia, que Chaplin, em princípio, quis sublimar de sua própria origem e, que, conforme temos argumentado a partir de um princípio de estabelecimento simbólico do cinema silencioso no mundo, ele mesmo representava. Para o senso comum, Chaplin já surgiu como um poeta das 
telas, como podemos ver no poema altamente laudatório que Carlos Drummond de Andrade (2002) lhe dedicou em 1945:

Para dizer-te como os brasileiros te amam e que nisso, como em tudo mais, nossa gente se parece com qualquer gente do mundo, inclusive os pequeno-judeus de bengalinha e chapéu-côco, sapatos compridos, olhos melancólicos, vagabundos que o mundo repeliu, mas zombam e vivem nos filmes, nas ruas tortas como tabuletas: Fábrica, barbeiro, Polícia, e vencem a fome, iludem a brutalidade, prolongam o amor como um segredo dito no ouvido de um homem do povo caído na rua. (ANDRADE, 2002, p. 190-191).

Mesmo o próprio Chaplin renega, em sua autobiografia, seu nascimento no paradoxo e na violência. A ideia, um tanto quanto romântica, de que o personagem Carlitos veio de um pulo só, espontaneamente, referendando o suposto gênio natural de Chaplin, é marcada de maneira vívida neste texto, muito lido e muito influente:

Eu não tinha a menor ideia sobre a caracterização que iria usar. Mas não tinha gostado da que apresentara como repórter. Contudo, a caminho do guarda-roupa, pensei em usar umas calças bem largas, estilo balão, sapatos enormes, um casaquinho bem apertado e um chapéu coco pequenino, além de uma bengalinha. Queria que tudo estivesse em contradição: as calças fofas com o casaco justo, os sapatões com o chapeuzinho. Estava indeciso se devia parecer velho ou moço, mas lembrei-me de que Sennett esperava que eu fosse mais idoso e, por isso, adicionei ao tipo um pequeno bigode, que, pensei, aumentaria a idade sem prejudicar a mobilidade da minha expressão fisionômica. Não tinha nenhuma ideia, igualmente, sobre a psicologia do personagem. Mas, no momento em que assim me vesti, as roupas e a caracterização me fizeram compreender a espécie de pessoa que ele era. Comecei a conhecê-lo e, no momento em que entrei no palco de filmagem, ele já havia nascido. Estava totalmente definido. Quando cheguei em frente de Mack, entrei no personagem, andando em passos rápidos, girando a bengalinha diante dele. Incidentes e ideias cômicas vinham em tropel à minha mente. (CHAPLIN, 1989, p. 141-142).

A origem violenta da poesia do cinema silencioso (convergida aqui na figura de Chaplin), portanto, é uma origem oculta, mas está associada a outros clichês ligados a este cinema. Afinal, o reconhecimento de Chaplin como espécie de "poeta das telas" se dá, em primeiro lugar, por sua performance e carisma, sendo ele, como diz Drummond (2002), "homem do povo caído na rua"? De certa maneira este raciocínio ratifica a noção, bastante comum, de que Chaplin teve de superar certa inconsistência original do cinema silencioso, 
como se tivesse de superar a si mesmo e, ao mesmo tempo, a inaptidão do medium, para fazer valer um tipo popular e celebratório de poesia. É por isso que a figura de Carlitos seria a de um homem desvalido, morador de rua muitas vezes, que enfrenta a fome e as mais diferentes adversidades, para seguir com resiliência e malandragem a sua trajetória errática. Sadoul (1963) foi um dos que ratificou esta visão: "Sua arte e poesia nascem não do cálculo longamente premeditado, mas da descoberta espontânea, da farsa e da prática constante." (SADOUL, 1963, p. 110-111).

Porém, sabe-se que a configuração da personalidade de Carlitos não foi tão instantânea e natural. Certos setores da sociedade, como críticos, burgueses e religiosos, começaram a se manifestar, ainda em 1915, contra o humor "vulgar" e cada vez mais popular que podia ser encontrado nos filmes de Chaplin. Em seus primeiros filmes na Keystone, Carlitos não era nem homogêneo (podendo ter personalidades e indumentárias distintas em cada filme) e nem flagrantemente "gentil", "poético" ou "homem do povo caído na rua". Maland (2004) realiza minuciosa reconstituição da trajetória dos filmes desta época e encontra Chaplin determinado a mudar a persona de seu alter-ego para poder angariar mais sucesso:

Como Chaplin respondeu a estas críticas? "0 novo Charlie Chaplin", um artigo de 1916 na Motion Picture Magazine, sugere não apenas que Chaplin estava consciente destes desafios à sua popularidade, mas também estava conscientemente começando a mudar e moldar sua imagem de estrela em resposta a eles. [...] No ensaio, Chaplin defendeu-se contra acusações de vulgaridade: "É por causa no meu treinamento e experiências com o musichall que... alguns fios de vulgaridade aparecem em minhas atuações." Ligando seu humor a uma tradição venerável, ele continuou: "Este estilo elisabetano de humor, esta forma crua de farsa e comédia slapstick... se deve inteiramente ao meu ambiente precoce, e estou agora tentando me livrar deste tipo de humor e me adaptar a uma forma mais fina e sutil de atuar". Este ensaio retrata Chaplin como aparentemente arrependido ou, ao menos, tomando cuidado para não antagonizar um grupo que poderia limitar sua popularidade. (MALAND, 2004, p. 204, tradução nossa).

Ainda que Chaplin fosse, sim, calculista e premeditasse seus passos em direção ao sucesso (o que fez com que ele transformasse a persona de Carlitos em poucos anos), é importante asseverar que a poesia no cinema silencioso, transfigurada de maneira tão clara e efetiva na comédia muda (Keaton, Lloyd e outros seguiram seus passos), pode estar enraizada nesta dicotomia original que é a violência fundando a mobilidade da mise-en- 
scène: a poesia silenciosa nasce e se desdobra, neste caso, da violência para o movimento, e o movimento, dotando a imagem de plasticidade ergonômica que encantava as primeiras plateias, é privilegiado pela ausência do som, medium concorrente que vai romper este equilíbrio anos depois. Daí tantos filmes importantes do cinema silencioso se balizarem na cinética muda para produzirem alumbramento.

A poesia de Chaplin (aqui metonímia para todo o cinema silencioso) se funda, portanto, como qualquer poesia, no paradoxo. Por mais que seu personagem tenha se transformado e se acomodado a condições sociais e econômicas do cinema de sua época, é justamente nesta dupla progressividade (o fato de ele "nascer pronto" e ao mesmo tempo "se construir estética e socialmente") que esta poesia encontra um princípio que corrobore as ideias de Zambrano (1996). 0 Chaplin maduro guarda a reminiscência de sua violência original. 0 Chaplin primevo já tinha, em si, o encanto que, mais elaborado adiante, o levaria ao estrelato absoluto. Poesia e filosofia, diria a filósofa, são potências gêmeas, que nascem do estupor, e são codependentes no caldo comum que as funda. Se a mesma cinética das imagens em movimento vai se bifurcar, como aponta Deleuze (1983), em imagensmovimento (a narrativa cinematográfica) e imagens-tempo (a emulação da passagem bergsoniana do tempo que nasce da busca pelo espaço cinematográfico), esta reminiscência inaugural também aponta caminhos distintos para o cinema. 0 vértice da ficção balizado pela fala apontará para o desbravamento do mundo (continuado na violência) iniciado na filosofia. 0 vértice documental terá sua própria maneira de representar. 0 terceiro vértice, 0 da poesia, vai procurar sublimar a violência inaugural e buscar unidade com o mundo por meio do fenômeno que o embala, que é o movimento.

Bergson (2010, p. 14) procurava alertar a respeito da possibilidade de se confundir "movimento" com "espaço percorrido" (algo que ainda perdura no senso comum). No caso de Chaplin, não se trata disso. A mecânica que envolve o dinamismo disparado pela violência inaugural funciona como Máquinas de Goldberg imaginárias: Chaplin pisa em uma tábua, que arremessa um balde, que cai na cabeça de seu antagonista, que corre atrás dele e pisa no rabo de um cachorro, etc. 0 movimento, neste caso, aparece como algo que possui existência autônoma. Ele é mais importante que o seu objeto. Neste sentido, fica a meio caminho da definição de Deleuze: “[...]o movimento será a passagem reguladora de uma forma a outra, uma ordem de poses ou instantes privilegiados." (DELEUZE, 1983, p. 9). Para ele, a passagem de uma forma a outra é necessariamente reguladora, ou seja, pressupõe uma mudança de estado em instantes privilegiados. Deleuze (1983) supõe que só há real 
movimento quando estas mudanças de estado ocorrem na matéria (no sentido bergsoniano), provocando um acontecimento. Portanto, não se trata somente de uma forçamotriz. Não se trata de uma mecânica. 0 movimento em Chaplin pode começar desta forma (como uma mecânica), mas termina, para fins de constituir um cinema poético, no movimento deleuziano. E nada disso poderia ocorrer, conforme veremos adiante, sem que sua imagem fosse silenciosa. É neste ínterim que se constitui a gramática de pura cinética, a intrincada coreografia do espírito de que falava Auster (2002 apud KOBEL, 2008, p. 55, tradução nossa). Não à toa, o movimento de atores como Chaplin ou Buster Keaton é frequentemente associado à dança ou ao balé. Sadoul (1963) deixa isso claro: "Quase todos estes filmes têm a precisão e a graça de um balé, mas a sátira e a crítica social os tornam algo mais que brilhantes divertimentos." (SADOUL, 1963, p. 131).

Já em sua fase na Essaney (em 1915), Chaplin passaria a moldar Carlitos de maneira a deixar a atmosfera primal da violência ser transmutada na poesia que ratifica estas relações todas. Em $O$ vagabundo (1915), um dos mais reverenciados curtas desta época, a inteligência do cineasta já havia aprisionado as condições específicas do novo medium que ele passara a experienciar e dominar. Aqui, Carlitos encontra a possibilidade de salvar Edna Purviance, uma moça rural, de assaltantes, "vagabundos" como ele próprio. Ele consegue salvá-la, mas ao contrário do que ocorre em Carlitos e as salsichas (ANO) - em que ele procura passar a perna em Mabel Normand -, aqui vai se aproximar dela como ingênuo interesse romântico. Carlitos é então acolhido pela família de fazendeiros, passa a (tentar) trabalhar e no final impede que os mesmos vagabundos retornem para roubar o pai de Purviance. Mesmo tendo sido um herói, ao ficar sabendo que sua amada ficara noiva de outro homem, ele decide deixar um tocante recado e ir embora. 0 último plano do filme é o de Carlitos caminhando sozinho em uma estrada poeirenta, com seu andar característico, algo cômico, algo melancólico, indefinido, que se encaixa perfeitamente no vértice poético do cinema. Neste filme, o movimento e a violência continuam a existir. Gags com fogo, ancinhos, escadas, sacos de farinha, etc., firmam terreno ainda no velho Chaplin. Porém, este filme é já a investida definitiva no melodrama, misturando gêneros, explorando a intercomunicabilidade de cada um deles.

Se tudo o que foi argumentado aqui até agora pôde ser inferido a partir de um excerto escrito por Paul Auster (2002), também uma única cena de Chaplin pode cumprir este papel. Em Dois heróis (ANO), o filme da Keystone de pugilismo em que ele contracena com Roscoe Arbuckle, Chaplin não é mais que um mero coadjuvante. Aparece apenas em 
uma cena: quando Arbuckle vai entrar no ringue para confrontar um adversário maior e mais ameaçador que ele, Chaplin é o juiz. Sendo esta sem dúvida a melhor cena do filme (Figura 4), fica o registro de sua capacidade de transformar mera violência mecanizada de maneira bruta em um legítimo movimento deleuziano que faz instantes privilegiados (neste caso, cada fotograma do filme) operarem mudanças de estado nos acontecimentos envolvidos no processo. Chaplin sabia que seus movimentos e pantomima eram muito superiores aos dos atores e atrizes que contracenavam com ele na Keystone (CHAPLIN, 1998). A cena da luta, com a presença de Chaplin conduzindo o balé mecânico, produz um efeito (de reincidência do instante) para cada pequeno movimento, cada tombo, cada soco dado no ar, com os três personagens se enlaçando como se fossem um fenômeno atmosférico, algo fortuitamente natural. Como se a violência do pensamento (que engendra a filosofia), por meio destes movimentos, operasse uma mudança de estado para estes instantes. Uma mudança para uma frequência poética.

Figura 4 - Chaplin como juiz de boxe

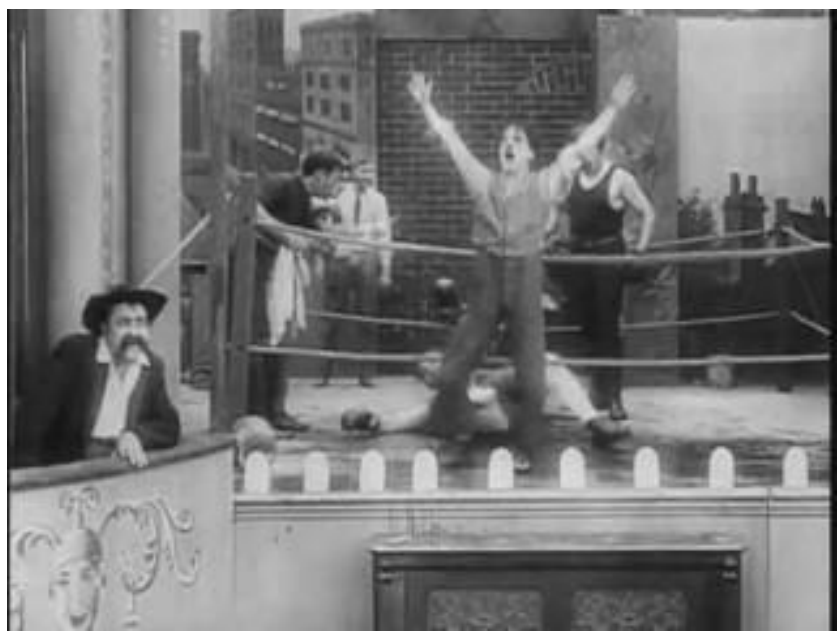

Fonte: Dois Heróis (1914).

\section{Financiamento}

Universidade Católica de Brasília.

Universidade de Brasília.

Coordenação de Aperfeiçoamento de Pessoal de Nível Superior (CAPES). 


\section{Referências}

ANDRADE, Carlos Drummond de. A rosa do povo. Rio de Janeiro: Record, 2002.

BERGSON, Henri. Matéria e memória. Ensaio sobre a relação do corpo com o espírito. São Paulo: Editora WMF Martins Fontes, 2010.

BOWSER, Eileen. The transformation of cinema. 1907-1915. Berkeley: University of California Press, 1990. (History of the American cinema; volume 2)

CHAPLIN, Charles. Minha vida. Rio de Janeiro: José Olympio, 1989.

DELEUZE, Gilles. Cinema 1 - A imagem-movimento. São Paulo: Brasiliense, 1983.

EISENSTEIN, Sergei. 0 sentido do filme. Rio de Janeiro: Jorge Zahar, 2002.

EISENSTEIN, Sergei . Dickens \& Griffith. Genèse du gros plan. Paris: Stalker Éditeur, 2007.

EVERSON, William. American silent film. New York: Da Capo Press, 1998.

JOHNSON, Christopher. Derrida:a cena da escritura. São Paulo: Editora UNESP, 2001.

(Coleção Grandes Filósofos).

KOBEL, Peter. Silent movies: the birth of film and triumph of movie culture. New York: Hachette Book Group, 2008.

MALAND, Charles J. A star is born: american culture and the dynamics of Charlie Chaplin's star image, 1913-1916. In: GRIEVESON, Lee; KRÄMER, Peter. (org.) The silent cinema reader. Routledge: New York, 2004.

METZ, Christian. A significação no cinema. 2. ed. São Paulo: Perspectiva, 2004. (Debates). PASOLINI, Pier Paolo. Empirismo hereje. Lisboa: Assírio e Alvim, 1982.

PUDOVKIN, Vsevolod. Os métodos do cinema. In: XAVIER, Ismail (org.). A experiência do cinema. Rio de Janeiro: Edições Graal, 2003.

SADOUL, Georges. História do cinema mundial: I volume. São Paulo: Livraria Martins Editora, 1963.

XAVIER, Ismail . 0 discurso cinematográfico. São Paulo: Paz e Terra, 2005.

ZAMBRANO, María. Filosofia y poesia. Cidade do México: FCE, 1996.

\section{Imagens em movimento}


A GARAGEM. Direção: Roscoe Arbuckle. Produção: Roscoe Arbuckle. Intérpretes: Roscoe Arbuckle, Buster Keaton e outros. Los Angeles: Comique, 1920. The garage.

CARLITOS e Mabel se casam. Direção: Charles Chaplin. Produção: Mack Sennet. Intérpretes: Charles Chaplin, Mabel Normand, e outros. Los Angeles: Keystone, 1914.

DOIS Heróis. Direção: Mack Sennet, Charles Avery. Produção: Mack Sennet. Intérpretes: Charles Chaplin, Roscoe Arbuckle e outros. Los Angeles: Keystone, 1914. The knockout.

EM BUSCA do ouro. Direção: Charles Chaplin. Produção: Charles Chaplin. Intérpretes: Charles Chaplin, Georgia Hale, Mack Swain, Tom Murray e outros. Los Angeles: United Artists, 1925. The gold rush.

INTOLERÂNCIA. Direção: D.W. Griffith. Produção: D.W. Griffith. Intépretes: Mae Marsh, Robert Heron, Constance Talmadge, Lillian Gish e outros. Los Angeles: Triangle, 1916. Intolerance.

LUZES da cidade. Direção: Charles Chaplin. Produção: Charles Chaplin. Intérpretes: Charles Chaplin, Virginia Cherril, Florence Lee, Harry Meyers e outros. Los Angeles: United Artists, 1931. City lights.

O CIRCO. Direção: Charles Chaplin. Produção: Charles Chaplin. Intérpretes: Charles Chaplin, Al Ernest Garcia, Merna Kennedy, Henry Bergman. Los Angeles: United Artists, 1928. The circus.

O GAROTO. Direção: Charles Chaplin. Produção: Charles Chaplin. Intérpretes: Charles Chaplin, Jackie Coogan, Edna Purviance e outros. Los Angeles: Charles Chaplin Productions, 1921. The kid.

O GRANDE ditador. Direção: Charles Chaplin. Produção: Charles Chaplin. Intérpretes: Charles Chaplin, Paulette Goddard, Jack Oaki. Henry Daniel, Reginald Gardiner e outros. Los Angeles: Charles Chaplin Productions, 1940. The great dictator.

RUA da paz. Direção: Charles Chaplin. Produção: Charles Chaplin, Henry P. Caulfield. Intérpretes: Charles Chaplin, Edna Purviance, Eric Campbell. Los Angeles: Mutual, 1917. Easy street.

\section{Poetry and violence in the birth of the silent language: the case of Chaplin}

\footnotetext{
Abstract

The career of Charles Chaplin, especially in his phase at Keystone, has a foundation in two forms of violence: the first, the physical violence of the thrusts and punches that his character Charlie throws at his antagonists; And the second, the motor violence, the incessant movement through the film field
} 
and through the shots. This work proposes an analysis of this double valence of violence in Chaplin as the founding principle of silent cinematographic poetry: how does this motor and physical forms of violence turn into ballet? Chaplin's trajectory in his short films will be analyzed through a narrative and historical reconstruction of cinema, searching for the birth of filmic poetry.

\section{Keywords}

Charles Chaplin. Cinematigraphic poetry. Silent cinema. Violence. Cinema theory.

Recebido em 28/04/2019

Aceito em 26/06/2019 